\title{
Critical factors and guidelines for 3D surveying and modelling in Cultural Heritage
}

by

S. Gonizzi Barsanti, F. Remondino and D. Visintini

Reprinted from

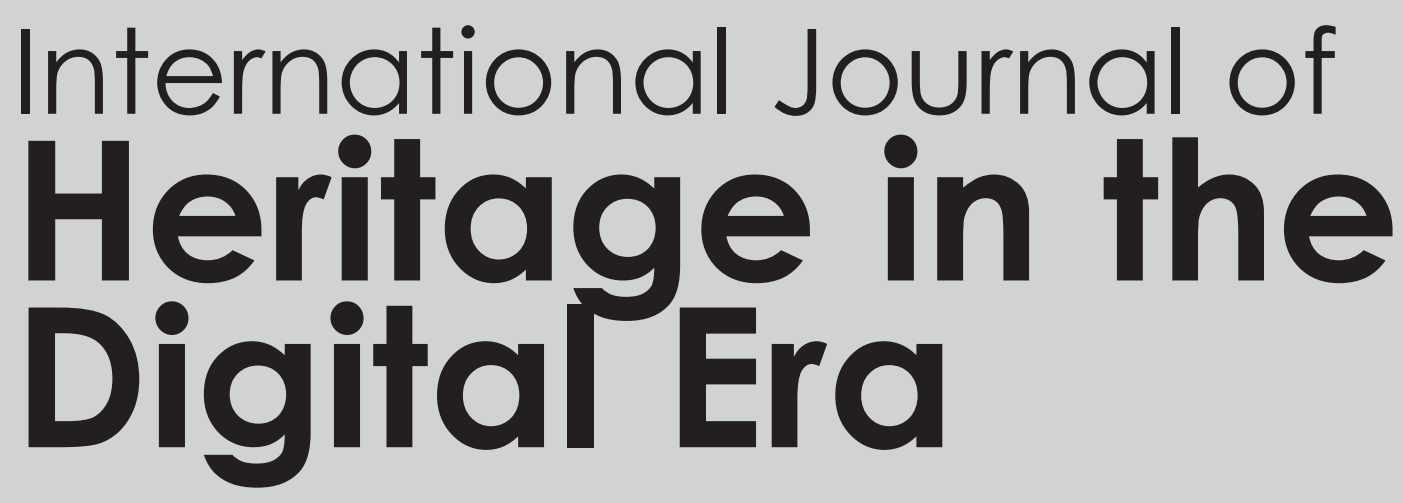

volume 3 number 12014 


\section{Critical factors and guidelines for 3D surveying and modelling in Cultural Heritage}

S. Gonizzi Barsantia, F. Remondinob, B. Jiménez Fenández-Palacios ${ }^{b}$ and D. Visintinic aDept. of Mechanics, Politecnico di Milano, Milano, Italy, sara.gonizzi@polimi.it

b3D Optical Metrology unit, Bruno Kessler Foundation (FBK), Trento, Italy, remondino@fbk.eu, bjfernandez@fbk.eu

'Dept. of Civil Eng. and Architecture, Univ. of Udine, Udine, Italy, domenico.visintini@uniud.it 


\title{
Critical factors and guidelines for 3D surveying and modelling in Cultural Heritage
}

S. Gonizzi Barsanti, F. Remondino, B. Jiménez Fenández-Palacios and D. Visintini

\begin{abstract}
:
The 3D digitization of sites or objects, normally referred to "realitybased 3D surveying and modelling", is based on 3D optical instruments able to deliver accurate, detailed and realistic $3 \mathrm{D}$ results. Nowadays many non-experts are facing the 3D world and its technologies (hardware and software) due to their easiness of use but a not correct use leads to wrong results and conclusions. The goal of the article is to critically report the 3D digitization pipeline with some Cultural Heritage examples. Based on our experiences, some guidelines are drawn as best practices for non-experts and to clearly point out the right approach for every goal and project.
\end{abstract}

\section{Introduction}

For research, documentation, preservation and conservation issues in archaeology and Cultural Heritage field, it is very important to appropriately record, document and survey artefacts and sites as an accurate and complete 3D digital documentation is a prerequisite for further analyses and interpretations. One type of documentation in Cultural Heritage is the so-called direct survey, which involves measuring in direct contact of objects or excavation units, for example, using a calliper or tape measure: a survey of this type is highly timeconsuming and is not so accurate. A second type is related to the use of indirect techniques that make use of total stations, Global Navigation Satellite System (GNSS) and 3D optical instruments, which offer several advantages over the direct acquisition techniques: (i) the time used to perform the survey is much shorter and the accuracy is higher; (ii) they do not require contact measurements avoiding possible damages to the heritage objects; (iii) a wide range of low-cost sensors and processing algorithms have recently become available. 3D optical instruments for the 3D digitization of objects and sites [17] include imaging sensors [16] - mounted on satellite, aerial and UAV/RPAS platform [13] or hand-held - and ranging sensors like laser scanners or structured light instruments [23]. These two approaches are 
normally called image-based and range-based modelling (IBM and RBM, respectively). Often both approaches are integrated in order to exploit the intrinsic advantages of each one and overcome possible problems ([9], [6], [12]). If 3D optical instruments and related techniques are employed for the 3D digitization of sites or objects, we generally refer to reality-based 3D surveying and modelling in order to distinguish from computer graphics world where field measurements are normally not used [21].

Following [15], the digital documentation and 3D modelling of Cultural Heritage should always consist of:

- Recording and processing of a large amount of 3D (possibly 4D) multi-source, multi-resolution, and multi-content information;

- Management and conservation of the achieved 3D (4D) models for further applications;

- Visualization and presentation of the results to distribute the information to other users allowing data retrieval through the Internet or advanced online databases;

- Digital inventories and sharing for education, research, conservation, entertainment, walkthrough or tourism purposes.

Following these actions, the paper summarizes the main 3D digitization steps, with some case studies to report technique's selections, critical factors and open issues. The article is intended to report different experiences in a critical way, describing design variables, designated methods and achieved results for each project. More technical details about the processing pipeline is outside the scope of the paper, which is more intended for non-experts in the heritage field to understand the best $3 \mathrm{D}$ digitization solution for a certain scenario. The reported case studies should provide a statistically adequate sample of which important conclusions can be drawn. Best practices related to data collection and processing were presented in ([3], [2], [19]).

\section{The 3D Digitization Pipeline}

Every project which aims to create 3D data starting from field measurements performed with active or passive sensors should follow these steps:

1) Site overview or object examination;

2) Study the project requirements and specifications;

3) Select the appropriate 3D recording technology or a combination of multiple technologies (sensors, targets, light, scale bars, etc.);

4) Select the appropriate representation and format of the results (mesh, parametric, volumetric, sections, grid/DEM, CAD, etc.);

5) Data acquisition planning; 
6) Sensor configuration design and parameter settings;

7) Data acquisition workflow based on best practice;

8) Data processing;

9) Quality check;

10) Results delivery.

The first four steps are very often denied and skipped, unfortunately. Select and use the wrong 3D recording technology and sensor may lead to failure in achieving the project requirements. This is one of the main reasons why 3D digitization has not yet reached its maximum potential, in particular in the heritage field, where many non-experts are using 3D technologies (hardware and software) without the right background. We can safely say that both imaging and ranging technologies are capable of providing similar accuracy and resolution when supported by a well-designed digitization plan and processing methods. Thus, before selecting between the two, one must (i) determine the design parameters for each technique to match the required accuracy and resolution and (ii) be able to process the collected data with the right algorithms.

The data acquisition phase must be performed in the best possible way guaranteeing an efficient planning of sensor positioning to ensure (i) optimum (i.e. lowest number) sensor positions, (ii) complete object coverage - with sufficient overlap for partial data registration and (iii) the required geometric accuracy of the final 3D result. Once data are acquired (images, scans, single points, etc.), ad-hoc (post-)processing operations allow to derive dense point clouds, polygonal models, orthoimages, sections, maps and drawing or further products useful for analyses, interpretation, conservation, etc.

In case of images, camera calibration and image orientation procedures are two fundamental steps required to derive 3D metric results. Fully automated structure from motion approaches (i.e. a simultaneous determination of camera interior parameters, camera poses and 3D object coordinates) are getting quite common, although their reliability is still challenging in particular for large scenarios [18]. The successive surface measurement step is normally performed with dense image matching algorithms, which have demonstrated great versatility and accurate results in the generation of high quality 3D data of complex scenes [20].

In case of ranging sensors, the acquired 3D point clouds need to be align into a common coordinate system by means of a similarity transformation and using complementary devices like CMM or reference targets/points surveyed with an independent technique (e.g. total station) or applying an Iterative Closest Points (ICP) method. 
Once a point cloud is obtained, a polygonal model is normally produced with ad-hoc algorithms available in several 3D modelling software packages. There are different ways to design the data structure or representation (e.g. point-based, direct meshes, exact/parametric surface-based splines, etc.). Each one has its advantages and disadvantages and should be considered as part of the project requirements and specifications. Finally the created polygonal 3D model can be textured for photorealistic visualization. Further products like orthoimages, sections and contours can be derived.

For the quality check of the achieved 3D results, different approaches and methods are available although standards for measuring the performance of a 3D system are still not available [1]. Most of the applications using 3D models require such models to be geometrically and visually accurate and free from noise, outliers and missing data or holes. Not only such errors make the models unusable for documentation or reproduction but also create unpleasant visual experience. The details should be of high quality, generally defined as high geometric accuracy or small uncertainty and completeness. The generated 3D coordinates must be always coupled with terms of a \pm uncertainty to give a range within which true measurement falls. If known geometric shapes (e.g. spheres or cube reference objects) are employed for the algorithms and results evaluation, the accuracy analysis can be performed using evaluation parameters defined in the VDI/VDE guidelines. On the other hand, if no ground-truth is available, uncertainty is expressed by the standard deviation $\sigma$ of the computed 3D coordinates (or multiples of it): for photogrammetric applications, a value for each 3D point can be derived, for active sensors a unique value for the entire 3D cloud is normally provide. Evaluations of 3D surveying and modelling techniques in the heritage field were presented e.g. in ([5], [8], [11], [14]).

\section{Test Sites and Objects}

The next sections report five 3D digitisation case studies with different types of movable and unmovable heritage objects. Each case study contains information about the actual artefact or monument being digitised, the purpose behind each case study, a short description of the data collection and processing phases along with the achieved results and the final use of the 3D models. The primary goal is to explain how to act in certain situations and deliver practical guidelines for non-experts. Each example differs in terms of object dimensions, material and digitization aims. 


\subsection{The Byzantine walls of Aquileia}

The Byzantine walls of Aquileia (Fig.1) date to the end of the fifth century AD or to the middle part of the sixth century AD. The remains of the fortifications are visible on the ground and in the modern cadastral divisions in the western part of the city. The site spans approximately $60 \times 40 \mathrm{~m}$.

\subsubsection{Scope of the 3D digitization}

The final goal of the project was to produce high-resolution orthoimages of the entire site and its walls' façades together with two main sections of the complete heritage area. This data were then used to create further 2D deliverables (maps and digitization plans) to highlight the different construction phases, analyze and study the history of the site as well as preservation and restoration issues.

\subsubsection{Project constraints and selected $3 D$ recording technique}

Given the morphology of the site, its complexity and also due to the bad condition of the archaeological structures, the entire site was surveyed using a UAV and TOF laser scanning in order to have a complete coverage of the structures. At the same time, terrestrial images were employed for the surveying of specific walls (those interested by collapses and restorations) and texturing reasons. The presence of several high trees encumbered the visibility of parts of the walls. Thus the integration of all surveying techniques helped to have a final complete documentation of the archaeological structures.

\subsubsection{D Surveying and modelling}

An initial survey was performed with a total station to acquire Ground Control Points (GCP) for scaling, merging and geo-reference purposes.

The laser scanning survey required 22 positions to digitize the site with a varying sampling step (from $3 \mathrm{~mm}$ to $12 \mathrm{~mm}$ at $10 \mathrm{~m}$ distance) and collecting ca 150 mil. points. A final polygonal model of 127 mil. polygons was then produced.
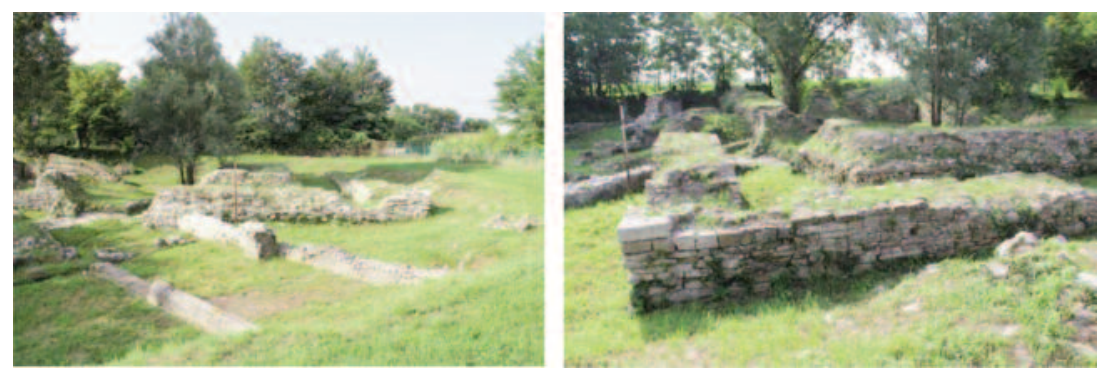

Figure 1. Two images of the city walls in Aquileia (Italy). 
The terrestrial images were acquired with a SLR camera and an average Ground Sample Distance (GSD) of $5 \mathrm{~mm}$. The imaging network was carefully planned due to the flatness and length of the walls, in order to avoid possible deformations in the 3D reconstruction. The image blocks were processed to produce dense point clouds and orthoimages of the wall façades.

Finally, the UAV survey was performed with a Quad copter manually piloted leading to a flight altitude variable between 15 and $25 \mathrm{~m}$, covering the entire archaeological area with an average GSD of 6-8 $\mathrm{mm}$. The photogrammetric processing of the UAV block, georeferenced with the available GCP, allowed the creation of an orthoimage

\subsubsection{Results and products}

The 3D data from both techniques were used as a support for the documentation and restoration of the heritage site. The 2D data derived from the processed terrestrial images (Fig. 2a), namely digitization and map products, were useful for the preservation of the walls, to identify the modern restoration, to map the original part of the structure, to highlight the fractures and create a construction phase's map. The UAV data, georeferenced and scaled using the total station survey data, were used to produce a plan of the site and to highlight the different visible phases (Fig. 2b, 2c). The site is composed of three main phases: the older, in blue in the image, is probably a warehouse or a public building, the second in time is the red one - a tower related to the first defensive buildings of the city -and the latter, in yellow, is the phase related to the Byzantine city walls.

Figure 2. The digitalization results of a wall showing restorations and fractures (a). The orthoimage of the entire site, with highlighted the walls and the requested sections (b) and the final map with the three different construction phases (c).
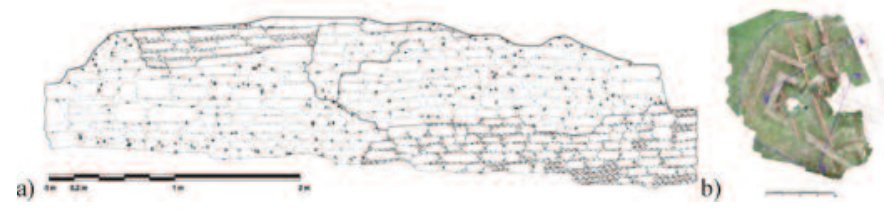

c)

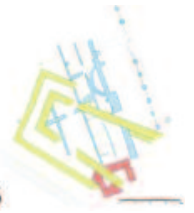

\subsection{San Galgano abbey}

The abbey of Saint Galgano (Fig. 3a) with the Montesiepi hermitage rise in the valley of the river Merse, between the medieval villages of Chiusdino and Monticiano, in the province of Siena (Italy). The construction started in 1218 and has been consecrated in 1288. For uncertain reasons the Abbey was abandoned in the XIV century and in the middle of the XVI century one monk decided to sale the roof of the church. This started the definitive abandonment and the Abbey 


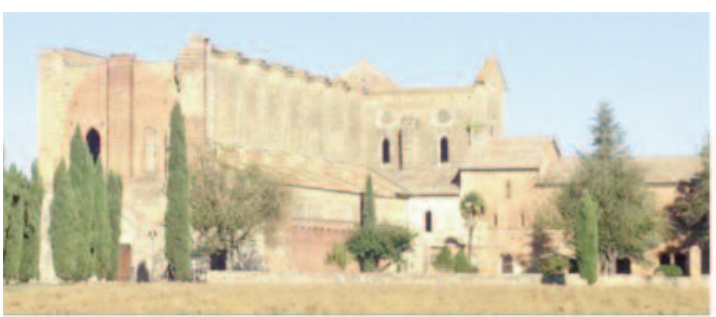

a)

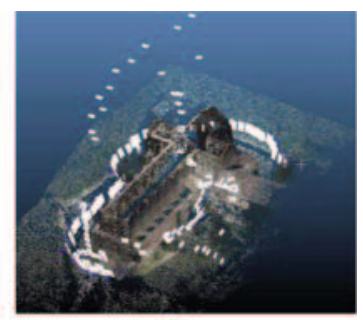

b)

Figure 3. The Abbey of San Galgano close to Siena, Italy. (a) The imaging network (ca 200 images) for the surveying of the complete Abbey (b).

become an enormous quarry of stones and columns for all the buildings of the zone. Since some decades, many jobs of restoration and maintenance have been undertaken. The Abbey spans ca $70 \mathrm{x}$ $20 \mathrm{~m}$, with a height of ca $20 \mathrm{~m}$.

\subsubsection{Scope of the 3D digitization}

Within the restoration and maintenance activities, a detailed and accurate survey of the historic church was necessary in order to produce a high-resolution orthoimage of the main façades and a map of the building. Archaeologists are interested in studying the building and the masonry techniques and in the restoration and conservation of the comple xstructure. Therefore, metric raster products are essential to have accurate information for the analysis and the mapping of the building, for the diachronic study of the structures and masonry techniques, the valorization of the archeological site and to analyze possible restoration and reinforcement operations.

\subsubsection{Project constraints and selected 3D recording technique}

Terrestrial and UAV photogrammetry were integrated to have a complete documentation of the Abbey, taking advantage of the absence of the roof. Indeed a UAV platform is ideal to observe the building from above and measure e.g. the thickness of the wall or the lower roof, while terrestrial images are ideal to complete the acquisition with higher resolution images. Around the Abbey the presence of trees occluded some parts of the walls therefore some areas were not fully visible during the surveying.

\subsubsection{D Surveying and modelling}

The UAV images were taken with a Droneforge MUAV which allow to collect with a Sony NEX7 both nadir and oblique images. The image resolution (GSD) and the UAV flight height were set in order to fulfil the requirement of the map scale (1:50). Terrestrial images were acquired all around the Abbey with a Nikon D3X in order to integrate the aerial views. Thanks to the oblique UAV images, the two image datasets 
Figure 4. The produced orthophoto (left) and the final map of the heritage at scale 1:50 (middle). The orthophoto of the south façade of the Abbey (right).
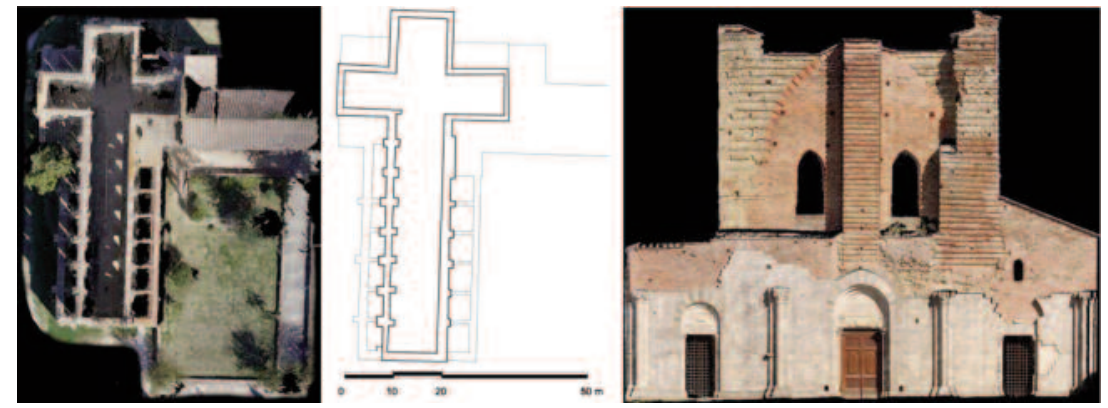

were processed together producing a complete 3D reconstruction of the heritage structure (Fig 3b). For scaling purposes, some distances were measured on sites.

\subsubsection{Results and products}

An orthophoto of the entire structure was produced at $5 \mathrm{~mm}$ resolution for the successive map generation (Fig. 4a,b). To create a map of the masonry techniques, a high-resolution orthophoto of the south façade was also produce (Fig. 4C). These 2D documentation products are useful for the analysis of construction techniques, construction phases and materials and to produce an informatics system for restoration and structural reinforcements issues.

\subsection{The etruscan Bartoccini's tomb}

The heritage dates back to VI century B.C. and is located in Tarquinia (Italy). The tomb, excavated in the hard sand, has four rooms - a central one (ca. 5x4m) and three later rooms (ca. $3 \times 3 \mathrm{~m}$ ) - all connected through small corridors. The height of the tomb rooms does not exceeds 3 meters and most of the sealing feature bass-reliefs. Inside the rooms, the walls are still painted with a reddish colour and figures (Fig. 5).

\subsubsection{Scope of the 3D digitization and constraints}

The project required a textured and accurate 3D model of the underground heritage for conservation, preservation and visualization purposes. So, at the same time, a "light" product to be easily visualized but accurate for documentation purposes. Conservators, using the metric information of the digital 3D replica, could evaluate the amount of material needed to restore walls and frescoes. A rendering of the digitized heritage was instead used for virtual visits and multimedia exhibitions. 


\subsubsection{Project constraints and selected 3D recording technique}

Etruscan tombs feature a downhill stairway ("dromos") and then different rooms connected by narrow corridors. Niches or sarcophagus inside the rooms produces many perspective occlusions notwithstanding the lack of texture except for some frescoed areas. The possible frescoes and painted figures on the walls of the tombs are particularly sensitive to any microclimate variation (humidity, temperature, vibrations) so only cold lamps and few people are allowed in the rooms for short time. The cramped spaces do not allow for any redundancy in the data and a weak geometry in the sensor positioning. Photogrammetry is thus not well suited due to the multiple occlusions, narrow spaces, smoothed geometry, uniform texture as well as bad illumination conditions. For all these reasons, excluding some multi-spectral analyses that required dedicated imaging sensors on small and specific areas, the suggested $3 D$ surveying technique for this kind of underground structures is $3 D$ laser scanning. TOF or phase-shift active sensors are able to provide for a dense 360 degrees point cloud from a single station even in case of dark environment and textureless surfaces. High-resolution digital images were separately acquired with a calibrated camera for texture mapping, orthoimage generation and frescoes documentation.

\subsubsection{D surveying and modelling}

The tomb was surveyed starting from the entrance. The point clouds of each room are positioned relatively to the others through a sort of concatenation and using the overlapping data. To speed up the acquisition phase, the scans were carefully planned before the campaign based on some sketches and old maps. The scanner was placed on a topographic tripod at a height which allowed recording the top of the burial beds located inside the rooms but also the sealing of the narrow corridor between the rooms. The average scan resolution is $5 \mathrm{~mm}$, a sufficient resolution according to the project requirements and needs. Once a unique point cloud was obtained, it was subsampled in order to reduce points in flat areas still keeping a good sampling in the areas with geometric discontinuities. Finally, a polygonal model was produced and textured using high-resolution images acquired with a SLR camera mounted on a panoramic head. The panoramic head allowed producing a panoramic/spherical image, which was then accurately mapped onto the geometry (Fig. 5).
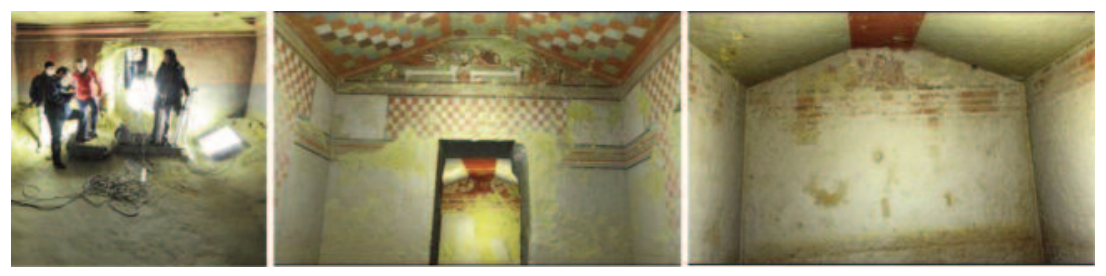

S. Gonizzi Barsanti, F. Remondino, B. Jiménez Fenández-Palacios and D. Visintini and
Figure 5. The Bartoccini Etruscan tomb in Tarquinia, Italy: the data acquisition phase (left) and some views of the produced $3 D$ model with texture. 
Figure 6. The produced and exploded 3D model of the heritage structure (left) and its visualization in the NUBES platform (right).
Figure 7. The statue of the Archangel Gabriel - images before and after the mounting of the scaffolding and a detailed view of the face of the bronze statue.
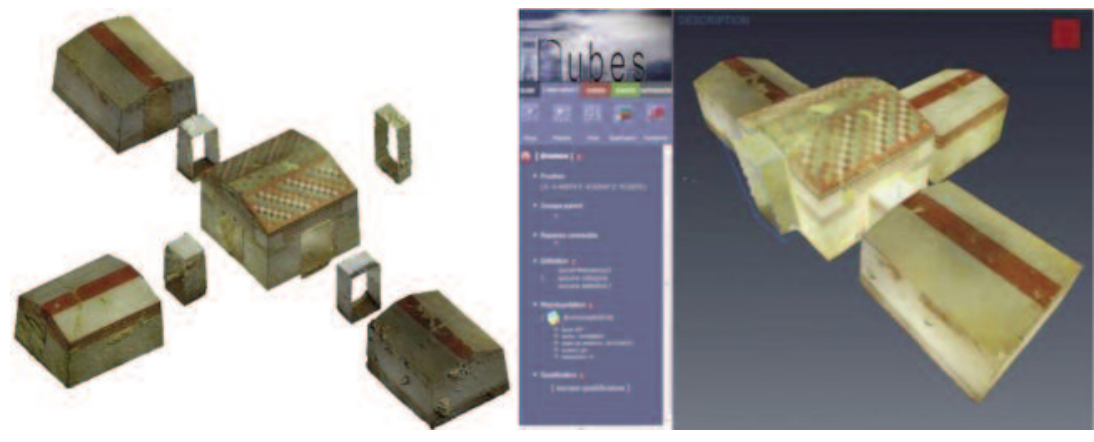

\subsubsection{Results and products}

The textured polygonal model (Fig. 6) was employed to produce animations (public's engagement), sections, maps and high-resolution orthoimages of the frescoed walls. Given the large dimension of the produced 3D data (ca 3 mil. polygons, $115 \mathrm{MB}$ jpeg texture) and to allow interaction and access to the 3D digital artefact, a remote rendering access was also created using the NUBES platform ([4], [10]).

\subsection{The bronze statue of the Archangel Gabriel}

The Archangel Gabriel statue in Udine (Fig.7) is a bronze object located on the top of the bell tower of the church of Santa Maria di Castello in Udine (Italy). The statue was made in the 17th century in golden bronze and had the purpose of indicate the direction of the wind with the finger of its right hand. Because of static problems, the mechanism that allowed the statue to turn around following the direction of the wind was blocked and the statue lost the most part of the golden plating. A restoration project started in 2011 to give back its ancient glory to the statue and, soon after the completion of the restoration of the bell tower, its rotating mechanism. The statue is ca $5 \mathrm{~m}$ high while from the finger to the wings it measure approximately $4 \mathrm{~m}$.

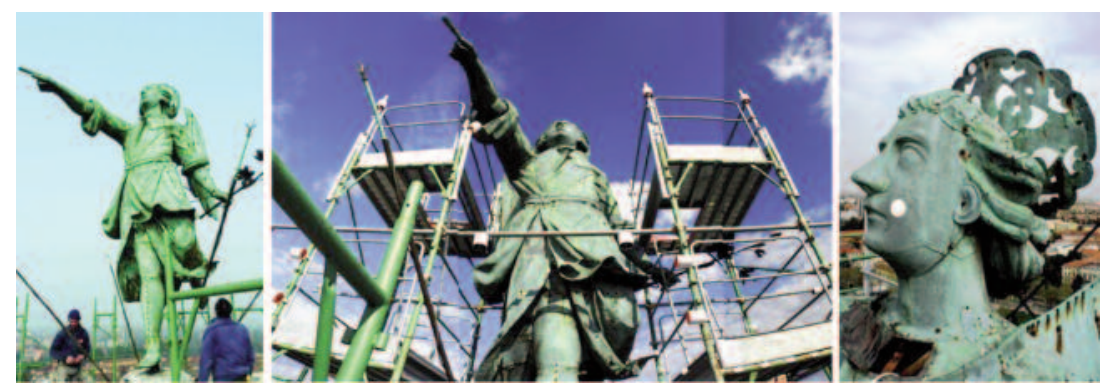




\subsubsection{Scope of the 3D digitization}

The 3D digitization of the statue aimed to produce orthoimages of the four sides of the monument and real prospects in scale 1:10 as metric base of the entire restoration project.

\subsubsection{Project constraints and selected 3D recording technique}

The material, shape, color and location of the statue suggested to use a TOF laser scanner for the 3D surveying. Moreover the small scaffolding mounted around the statue was not ideal to achieve a good imaging network and so 360 degrees FOV laser scanner with an integrated calibrated camera rigidly fixed to the head of the scanner was chosen. The scaffolding was severely secure not to have any vibration but caused occlusions during the data acquisitions.

\subsubsection{D Surveying and modelling}

The range instrument was placed in 10 positions to ensure the entire coverage of the statue and the average sampling step of acquired point clouds was $3 \mathrm{~mm}$. Simultaneously, the embedded camera acquired the images necessary for the texturing of the final 3D model. To facilitate the range data registration, some high reflectivity cylindrical or circular targets were placed on the statue. The entire point cloud was segmented according to architectural and archaeological rules and to facilitate the mesh model generation. Indeed the statue is composed of some parts with low curvature (e.g. the wings) and of other complex curved shapes with very small elements and details (e.g. the cuffs of the dress). The obtained mesh was finally textured using the images acquired from the camera fixed on the head of the scanner.

\subsubsection{Results and products}

Using the created textured 3D model, for each side of the statue (namely West, North, East and South), an orthophoto projection was generated at ca $2 \mathrm{~mm}$ resolution. In this way, real prospects in scale 1:10 were produced (Fig. 8) for the subsequent manual 2D restitution of
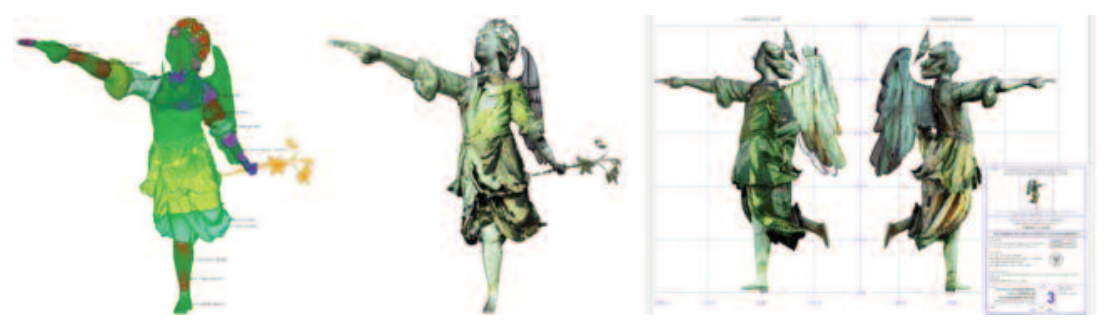

Figure 8. View of the segmented point cloud of the statue (left), the produced polygonal textured model (middle) and the 1:10 representations for restoration purposes (right). 
the various elements that make up the surface of the statue such as outlines, edges, patches, nails, folds of the dress, the tie rods, etc. Finally, similarly to [22], the statue was inserted in a VRML environment, allowing interactive exploration of the model in stereoscopic mode (with anaglyph glasses).

\subsection{Archaeological museum objects}

The artefacts reported in the next section (Fig. 9) belong to the collection of the Archaeological Museum of Milan. It consists of ca 2000 objects among different collections, Greek, Etruscan, Roman and early Medieval. The reported artefacts are a Roman marble statue dated back to the I century AD (ca 1,2 m high), a Roman funerary inscription (stele) of the I century $A D(2,1 \mathrm{~m}$ high) and a Greek ceramic vase dating back to the $\mathrm{V}$ century $\mathrm{BC}$ (ca $60 \mathrm{~cm}$ high).

\subsubsection{Scope of the 3D digitization}

The reported work is within the 3D digitization activities of the 3D-ICONS project (http://3dicons-project.eu/) whose aim is to produce a large number of textured 3D models (more than 3000) to feed Europeana and increase the critical mass of engaging 3D content available to Europeana's users. In Europeana, 3D models should be accurate for possible re-use but primarily the models should be suitable for web visualization. The Politecnico of Milano is in charge of producing more than 500 3D models [7].

\subsubsection{Project constraints and selected $3 D$ recording technique}

Before the survey, an inspection of museum rooms and artefacts was necessary to understand moving spaces, lighting conditions,

Figure 9. The three museum objects: a Roman marble statue (a), a Roman stele (b) and a Greek vase (c).

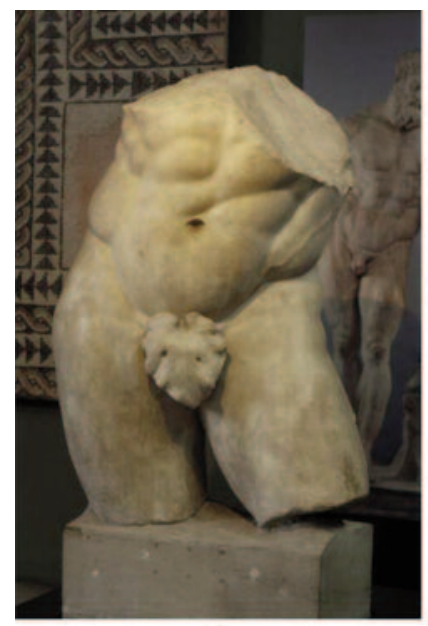

a)

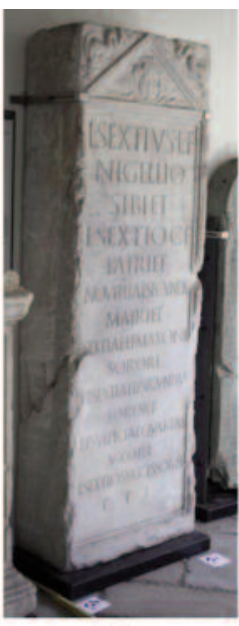

b)

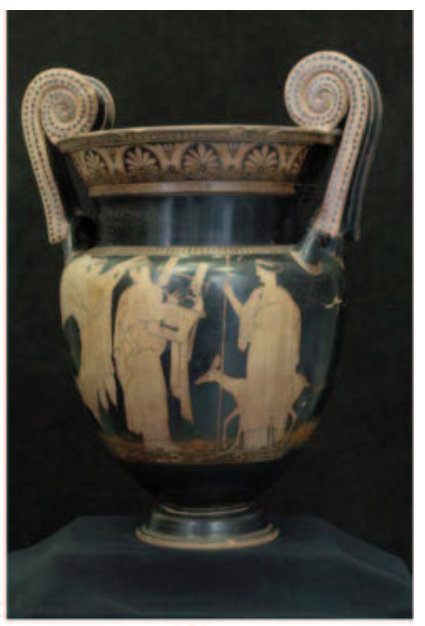

c) 
accessibility, etc. In the rooms, the windows produced significant backlight effects while most of the artefact had a lack of texture (marbles, black surfaces, restored parts, etc.). Considering all these matters, the final goal of the project and the large numbers of 3D models to be created, it was necessary to identify the best 3D surveying and modeling pipeline in terms of production time, accuracy and reliability. Photogrammetry was selected as a comprehensive technique able to deliver accurate 3D models with high quality texture in reasonable processing time. The use of triangulation-based scanner would have been too much time consuming and the material of the objects were more cooperative with an imaging technique.

\subsubsection{D Surveying and modelling}

Flat panels were employed to shield the backlight coming from the windows, avoid the strong light imbalance and the relatively dark foreground. Most of the surveyed objects were left fixed on their basement and the camera moved all around, using a dark cloth to facilitate the orientation and dense matching procedures. For all the image acquisition, a full frame SLR camera coupled with a $50 \mathrm{~mm}$ lens was used, collecting ca 20-30 images per artefact ensuring always a sub-centimeter GSD. A significant overlap with the images was mandatory to ease the successive automated processing. The data processing, carried out with automated procedure based on Structure from Motion and dense image matching algorithms produced textured 3D polygonal models which were afterwards optimized and decimated. For the ingestion into Europeana, meta- and para-data of each artefact were also collected.

\subsubsection{Results and products}

Following the project requirements, the final 3D models were converted in 3DPDF, in order to produce light, feasible and easy to access products simply navigable on low-end personal computers (Fig. 10a). High-resolution orthoimages and digitization products were also created for archaeological analyses(Fig. 10b and c).

\section{Conclusions}

Using reality-based 3D surveying and modelling techniques (namely photogrammetry and range sensors) it is possible to derive 2D and 3D metric data useful for heritage documentation and conservation, archaeological investigations, interpretation and analyses or simple visualization purposes to engage the public. The heritage field is in need of 3D digitization actions and these should be conducted by interdisciplinary groups where different expertise are joined together. 
Figure 10. Products of the 3D digitization of archaeological finds: 3DPDF for the statue(a); part of the digitize inscription on the highresolution orthoimage $(0.5 \mathrm{~mm})$ of the stele (b); orthoimage of the Greek vase and digitization (scale 1:1) of the decoration (c).
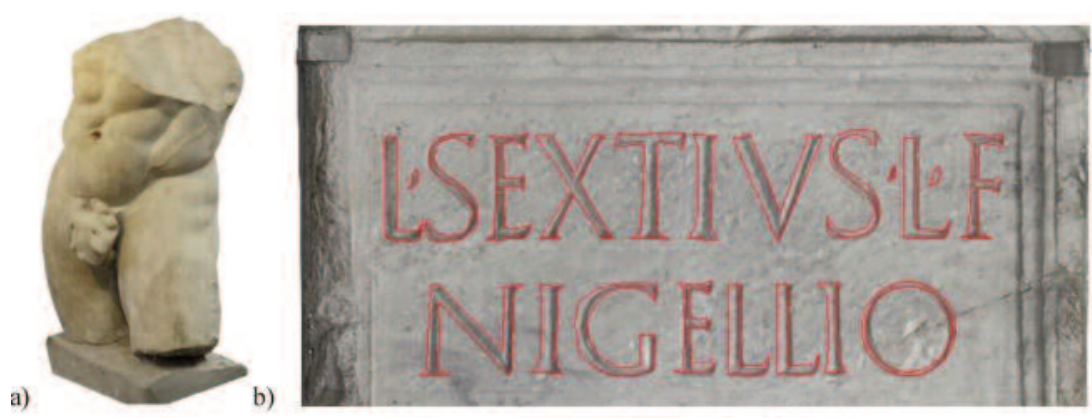

c)

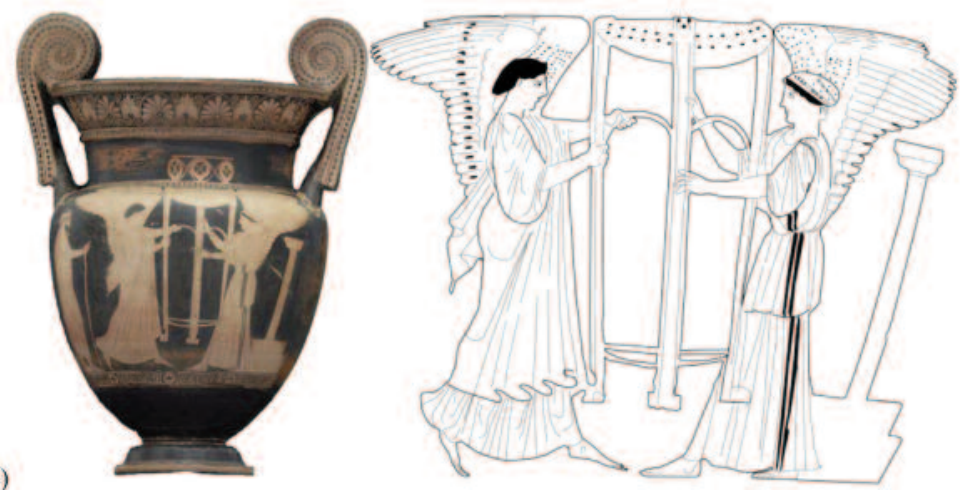

If the surveying phase (image acquisition or scanning) is nowadays more straightforward and easy than some years ago, the geometric and appearance modelling steps (from point cloud to a textured surface model) is still rich of problems and often the most time consuming part of the work where experiences and knowledge of the employed technique or software are mandatory. Open and low-cost software for data processing are available but their reliability is always a question in particular for large dataset and in case of highdemanding products and requirements.

Photogrammetry requires some experience and images have to be properly acquired, otherwise the results are not satisfactory, in particular with fully automated black-boxes tools. New fully automated methods (based on Structure from Motion techniques) are getting quite popular in the heritage field but metrics and reliability of such approaches are still very far away from being a successful solution. Laser scanning, on the other hand, is not so difficult to be used during the surveying, but it requires a lot of time and experience during the processing in the lab. Moreover, particularly for large site or buildings, the collected 3D data are usually difficult to deal with due to the heaviness of the models composed of a high number of polygons. This kind of data are quite impossible to be visualized with a standard laptop and require a high performance desktop computer to open and process them. 
Both surveying techniques have their advantages and disadvantages (Tab. 1). Several recent publications compared the two technologies based on factors such as accuracy and resolution. We argue that both technologies are capable of providing similar accuracy and resolution when supported by a well-designed digitization plan. Thus, before selecting between the two, one must determine the design parameters for each technique to match the required project's accuracy, resolution and need. In case of large and complex sites, a good solution still seems to be the combination of both methods, as each one has attributes and elements balancing the other one and in order to (i) use the fundamental strengths of each technique, (ii) make up for weaknesses of the methods, (iii) obtain different geometric Levels of Detail (LOD) of the scene and (iv) achieve more accurate and complete geometric surveying for modelling, understanding, representation and digital conservation issues.

From a research point of view, the entire 3D digitization pipeline is still lacking of different reliable procedures. Automation is just a small

\begin{tabular}{|c|c|c|}
\hline & $\begin{array}{l}\text { Photogrammetry } \\
\text { (image-based } \\
\text { modelling) }\end{array}$ & $\begin{array}{l}\text { Laser scanning } \\
\text { (range-based } \\
\text { modelling) }\end{array}$ \\
\hline \multicolumn{3}{|l|}{ Characteristics } \\
\hline $\begin{array}{l}\text { Cost of the instruments } \\
(\mathrm{HW} \text { and SW) }\end{array}$ & Low & High \\
\hline Manageability/Portability & Excellent & Sufficient \\
\hline Time of data acquisition & Quite short & Generally long \\
\hline Time for modelling & $\begin{array}{l}\text { Short but experience } \\
\text { required }\end{array}$ & Often long \\
\hline 3D information & To be derived & Direct \\
\hline Distance's dependence & Independent & Dependent \\
\hline Dimension's dependence & Independent & Dependent \\
\hline Material's dependence & Almost independent & Dependent \\
\hline $\begin{array}{l}\text { Light's dependence } \\
\text { independent }\end{array}$ & Dependent & Almost/totally \\
\hline Geometry's dependence & Quite dependent & Independent \\
\hline Texture's dependence & Dependent & Independent \\
\hline Scale & Absent & Implicit $(1: 1)$ \\
\hline Data volume & $\begin{array}{l}\text { Dependent on the } \\
\text { images resolution and } \\
\text { on the measurements }\end{array}$ & $\begin{array}{l}\text { Dense point } \\
\text { cloud }\end{array}$ \\
\hline $\begin{array}{l}\text { Detail's modelling } \\
\text { excellent }\end{array}$ & Good/excellent & Generally \\
\hline $\begin{array}{l}\text { Texture } \\
\text { resolution }\end{array}$ & Included & Absent/Low \\
\hline $\begin{array}{l}\text { Edges } \\
\text { problematic }\end{array}$ & Excellent & Quite \\
\hline Statistics & For each 3D point & Global \\
\hline Open-source software & Many & A few \\
\hline
\end{tabular}
and 
part of the work and, often, it is even the less important one. Indeed we need to keep always an eye on accuracy and precision, even in case of projects with visualization purposes, otherwise the entire digitization is useless and an image could be more useful. Noncooperative objects and materials (e.g. glasses, shiny surfaces, dark or untextured artefacts, etc.) are still problematic for actual 3D digitization methods and advanced methods for the digitization of such artefacts need to be realized.

\section{Acknowledgments}

The work was partly supported by the 3D-ICONS project funded under the EC's ICT Policy Support Programme. The Etruscan tombs were digitized thanks to the support of the Soprintendenza per i Beni Archeologici dell'Etruria Meridionale and Soprintendenza per i Beni Archeologici della Toscana and Historia (http://www.historiaweb.it). The authors are also thankful to the Soprintendenza per i Beni Archeologici del Friuli Venezia Giulia.

\section{References}

[1] Beraldin, J.-A., 2009: Basic theory on surface measurement uncertainty of 3D imaging systems. Proc.SPIE, Vol. 7239, pp. 7239-1-7239-12.

[2] Beraldin, J. A., Picard, M., Bandiera, A., Valzano, V., Negro, F., 201 1: Best practices for the 3D documentation of the Grotta dei Cervi of Porto Badisco, Italy. Proc. SPIE, Vol. 7864, pp. 78640J-78640J-15.

[3] Bryan, P., Blake, B., Bedford, J., 2009: Metric survey specifications for cultural heritage. English Heritage. http://www.englishheritage.org.uk/publications (accessed March 2014).

[4] De Luca, L., Bussayarat, C., Stefani, C., Véron, P., Florenzano, M., 2011: A semantic-based platform for the digital analysis of architectural heritage. Computers \& Graphics. Vol. 35(2), pp. 227-241.

[5] Doneus, M., Verhoeven, G., Fera, M., Briese, Ch., Kucera, Neubaver, W., 2011: From deposit to point cloud - A study of low-cost computer vision approaches for the straightforward documentation of archaeological excavations. Proc. 23 $3^{\text {rd }}$ CIPA Symposium.

[6] Fassi, F., Achille, C., Fregonese, L., 2011: Surveying and modelling the Main Spire of Milan Cathedral using multiple data sources. The Photogrammetric Record, Vol.26, pp. 462-487.

[7] Gonizzi Barsanti, S., Micoli, L.,L., Guidi, G., 2013. Quick textured mesh generation from massive 3D digitization of museum artefacts. Proc. IEEE Conference "Digital Heritage 2013", Vol. 1, pp. 197-201.

[8] Grussenmeyer, P., Landes, T., Voegle, T., Rongle, K. 2008. Comparison methods of terrestrial laser scanning, photogrammetry and tacheometry data for recording of cultural heritage buildings, Int. Archives of Photogrammetry, Remote Sensing and Spatial Information Sciences, Vol. 37(B5), pp. 213-218.

[9] Guidi, G., Remondino, F., Russo, M., Menna, F., Rizzi, A, Ercoli, S. 2009. A Multi-resolution methodology for the 3D modelling of large and complex 
archaeological areas, International Journal of Architectural Computing, Vol. 7(1), 39-55.

[10] Jiménez Fernández-Palacios, B., Stefani, C., Lombardo, J., De Luca, L., Remondino, F., 2013: Web visualization of complex reality-based 3D models with NUBES. Proc. IEEE Conference "Digital Heritage 2013", Vol. 1, pp. 701-704.

[1 1] Lahoz, J.G., Aguilera, D.G., Finat, J., Martínez, J., Fernández, J.J., San Jose, J., 2006: Terrestrial laser scanning metric control: assessment of metric accuracy for cultural heritage modelling. Int. Archives of Photogrammetry, Remote Sensing and Spatial Information Sciences, Vol. 36(5).

[12] Nex, F., Rinaudo, F., 2011: LiDAR or Photogrammetry? Integration is the answer. Italian Journal of Remote Sensing, Vol.43(2), pp. 107-121.

[13] Nex F., Remondino, F., 2013: UAV for 3D mapping applications: a review. Applied Geomatics, DOI 10.1007/s12518-013-0120-x.

[14] Opitz, R., Simon, K., Barnes, A., Fisher, K., Lippiello, L., 2012: Close-range photogrammetry vs. 3D scanning: comparing data capture, processing and model generation in the field and the lab. Proc. CAA

[15] Patias, P., 2007: Cultural heritage documentation. In "Application of 3D Measurement from Images", Fryer, J., Mitchell, H., Chandler, J.(Eds.), Whittles, UK, Vol. 59, pp. 225-257

[16] Remondino, F., El-Hakim, S. 2006: Image-based 3D modelling: a Review. Photogrammetric Record, Vol. 21 (115), 269-291.

[17] Remondino, F. 2011: Heritage recording and 3D modelling with photogrammetry and 3D scanning, Remote Sensing, Vol. 3, pp. 1104-1138.

[18] Remondino, F., Del Pizzo, S., Kersten, T., Troisi, S. 2012: Low-cost and opensource solutions for automated image orientation - A critical overview. Proc. Euromed Conference, LNCS 7616, pp. 40-54. Springer, Heidelberg.

[19] Remondino, F., Spera, M.G., Nocerino, E., Menna, F., Nex, F., 2013: State of the art in high density image matching. Photogrammetric Record, in press

[20] Remondino, F., Menna, F., Koutsoudis, A., Chamzas, C., El-Hakim, S., 2013: Design and implement a reality-based 3D digitisation and modelling project. Proc. IEEE Conference "Digital Heritage 2013", Vol. 1, pp. 137-144.

[21] Vanegas, C., Aliaga, D., Benes, B., 2010: Building reconstruction using Manhattan-World grammars. Proc. 23rd IEEE CVPR Conference, San Francisco, CA, USA, pp. 358-365.

[22] Visintini, D., Siotto, E., Menean, E. 2009: 3D modeling of the St. Anthony Abbot Church in S.Daniele del Friuli (I): from laser scanning and photogrammetry to VRML/X3D model. Int. Archives of Photogrammetry, Remote Sensing and Spatial Information Sciences, Vol. 38(5/W1).

[23] Vosselman, G., Maas, H. G. 2010. Airborne and Terrestrial Laser Scanning, 2010, CRC Press. 